\title{
Screening and prophylaxis of cancer
}

\author{
Holger Rumpold
}

Cancer is the second most common cause of death in developed countries, preceded only by heart diseases. Due to demographic changes, the number of cancer patients is rising and will increase to an estimated 15 million people in the United States by 2020 , for example. This increase is complemented by the recent progress in treatment of cancer. This has led to a significant increase of cancer-related survival rates across all entities. The success in the fight against cancer is further augmented by screening programs enabling the detection of cancer in early stages, when cure is more likely to be reached than in later stages.

Prevention of cancer has been a matter of debate for years: What is the influence of nutrition, physical activity, obesity, and various environmental factors such as ultraviolet radiation in the development of cancer? Because of many confounding factors, research aiming to answer this question is difficult. Sadly enough, this circumstance also favors the development of myths-especially if we consider nonevidence-based lifestyle recommendations, including special diets, to prevent cancer.

Screening programs show positive effects on the incidence of various cancers, which are well documented for cervical cancer, colon cancer, and breast cancer, for example. But despite this effort, the balance of "risk" (false positive results, frequency of examinations, psychological issues) and "benefit" (true positive results, prevention of cancer) is still a matter of debate in many screening programs. Broad screening for breast cancer by mammography and prostate-

H. Rumpold, MD ( $\varangle)$

Visceral Cancer Center, Ordensklinikum Linz,

Seilerstätte 4, 4020 Linz, Austria

holger.rumpold@ordensklinikum.at specific antigen measurements for early detection of prostate cancer are key examples illustrating the potential harm for overtreating indolent or harmless diseases.

However, prevention is more than only performing specific examinations in obviously healthy people. It is much better described as the "protection of health by personal and community-wide efforts," as defined by Miller and colleagues [1]. As well as describing the burden of disease, this also includes identification of the causes of cancer. Due to the efforts of clinical and experimental researchers in recent decades, many of these causes have been described and should be implemented into intelligent prevention strategies. The best example for that is the knowledge about HPVdriven urogenital and oropharyngeal cancer, which likely can be prevented by an HPV vaccine.

To prevent cancer is better than to treat cancer-this still holds true in our modern times. From this perspective, prevention programs play an important role in oncology. It is a challenge nowadays to implement detailed knowledge about cancer in prevention/screening strategies to "personalize" not only treatment but also prevention-for example, by the sophisticated identification of populations at risk.

In this issue of $M E M O$, screening and prevention issues are discussed for prostate cancer, cutaneous melanoma, colorectal cancer, and HPV-driven cancer.

The authors [2-4] have to be thanked and congratulated for contributing their careful work and their well-balanced discussions considering both the risks and the benefits to which people are exposed by screening/prevention measurements.

Conflict of interest H. Rumpold declares that he has no competing interests. 


\section{References}

1. Miller SM, et al. Primary prevention, aging, and cancer: overview and future perspectives. Cancer. 2008;113:3484-92.

2. Seidl-Philipp M, Nguyen VA. Cutaneous melanoma-The benefit of screening and preventive measures. Memo. 2019;12(3). https://doi.org/10.1007/s12254-019-0512-7.

3. Niederreiter M, Niederreiter L, Schmiderer A, Tilg H, Djanani A. Colorectal cancer screening and prevention—pros and cons. Memo. 2019;12(3). https://doi.org/ 10.1007/s12254-019-00520-z.

4. Heidegger I. PSA screening - a matter of debate? Memo. 2019;12(3). https://doi.org/10.1007/s12254-019-00524-9.

Publisher's Note Springer Nature remains neutral with regard to jurisdictional claims in published maps and institutional affiliations.

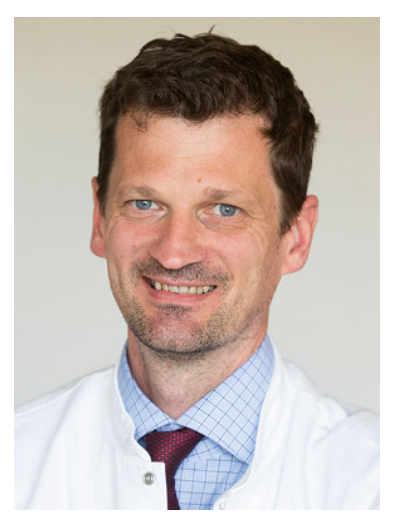

Holger Rumpold

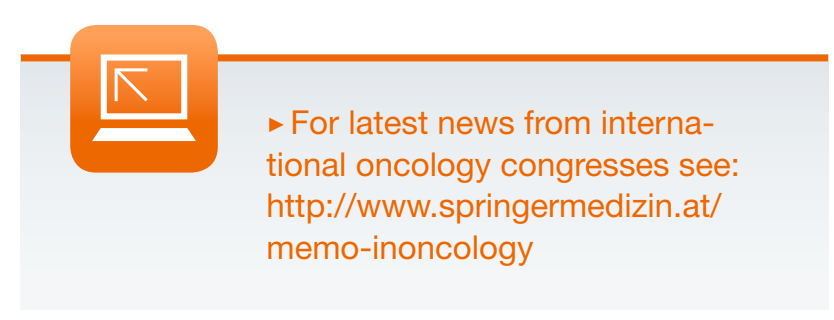

